\title{
Genetic variability of the P I 20' surface protein gene of Mycoplasma hominis isolates recovered from Tunisian patients with uro-genital and infertility disorders
}

\author{
Boutheina Ben Abdelmoumen Mardassi* , Hajer Ayari, Awatef Béjaoui-Khiari, \\ Béhija Mlik, Imed Moalla and Faten Amouna
}

Address: Laboratoire des Mycoplasmes, Institut Pasteur de Tunis, 13, Place Pasteur-B.P.74, 1002 Tunis-Belvédère, Tunis, Tunisie

Email: Boutheina Ben Abdelmoumen Mardassi* - boutheina.mardassi@pasteur.rns.tn; Hajer Ayari - hajer_a21@yahoo.fr; Awatef BéjaouiKhiari - awatef.bejaoui@yahoo.fr; Béhija Mlik - behija.mlik@pasteur.rns.tn; Imed Moalla - imedmoalla_ipt@yahoo.fr;

Faten Amouna - faten_amouna@yahoo.fr

* Corresponding author

Published: 5 December 2007

BMC Infectious Diseases 2007, 7:142 doi:10.1 186/147/-2334-7-142
Received: 28 April 2007

Accepted: 5 December 2007

This article is available from: http://www.biomedcentral.com//47I-2334/7//42

(C) 2007 Mardassi et al; licensee BioMed Central Ltd.

This is an Open Access article distributed under the terms of the Creative Commons Attribution License (http://creativecommons.org/licenses/by/2.0), which permits unrestricted use, distribution, and reproduction in any medium, provided the original work is properly cited.

\begin{abstract}
Background: Among the surface antigens of Mycoplasma hominis, the PI20' protein was previously shown to elicit a subtle antibody response and appears to be relatively conserved. To get better insight into the evolution of this protein, we analysed the genetic variability of its surface exposed region in $27 \mathrm{M}$. hominis isolates recovered from the genital tract of Tunisian patients with infertility disorders.
\end{abstract}

Methods: All specimens were processed for culture and PCR amplification of the $\mathrm{N}$-terminal surface exposed region of $\mathrm{p} / 20^{\prime}$ gene. PCR products were sequenced to evaluate the genetic variability, to test for adaptive selection, and to infer the phylogenetic relationship of the M. hominis isolates.

Results: Sequence analysis showed a total of 25 single nucleotide polymorphisms distributed through 23 polymorphic sites, yielding 13 haplotypes. All but one mutation were confined within three distinct regions. Analysis of the amino acid-based phylogenetic tree showed a predominant group of 17 closely related isolates while the remaining appear to have significantly diverged.

Conclusion: By analysing a larger sample of $M$. hominis recovered from patients with urogenital infections, we show here that the PI20' protein undergoes substantial level of genetic variability at its surface exposed region.

\section{Background}

Mycoplasma hominis belongs to the class Mollicutes, the smallest cell-wall free prokaryotic organisms. Mycoplasmas are considered to be a clostridial branch of Gram positive eubacteria and were supposed to have lost a large part of genomic material and metabolic pathways during their evolution [1,2]. Recently, the M. hominis genome size was reported and shown to be composed of $665,445 \mathrm{kpb}$ with $27 \mathrm{~mol} \%$ of G+C [3]. M. hominis is an opportunistic pathogen causing gynaecological infections [4]. It has been associated with pyelonephritis, pelvic inflammatory disease, and postpartum septicaemia [5]. M. hominis is 
increasingly detected in extragenital infections [6], infants born to infected mothers became infected with these bacteria [7] and colonization of the respiratory tract of infants has been associated with pneumonia and meningitis $[8,9]$.

Like the majority of mycoplasma species, M. hominis appears to be equipped with a genetic system that allows it in vivo to alter its surface exposed, membrane-associated, antigenic repertoire. Three surface membrane proteins, P120, Lmp, and Vaa, whose products undergo genetic variability could account for the ability of this microorganism to circumvent the host immune system [10-13]. The highly antigenic P120 gene displays a hypervariable region due to accumulation of mutations, while Lmp1 and Lmp2 genes show size variations and could be expressed as a chimearic protein. The Vaa gene product, which is involved in cell adherence, displays both size variation and frameshift mutation to create variant products. However, an additional surface protein, related to the variable P120 was identified and named P120' [10]. In contrast to the former, $\mathrm{P} 120^{\prime}$ appears to be particularly conserved and weakly recognised by sera from patients with M. hominis confirmed infection. It has been speculated that P120 and P120' could have evolved by gene duplication followed by sequence divergence, whose extreme counterpart example is represented by the pMGA gene family of the avian Mycoplasma gallisepticum $[14,15]$.

In the present study, we show that the N-terminal surface exposed region of the P120' protein undergoes substantial genetic variability within strains isolated from patients displaying urogenital and infertility disorders.

\section{Methods}

\section{Mycoplasma strains and growth media}

Five reference strains of human mycoplasmas, three ureaplasma isolates, and 27 mycoplasma clinical isolates were used: Reference strains were purchased from the American Type Culture Collection (ATCC): M. hominis PG21 (ATCC 23114), M. fermentans (ATCC 19989), M. genitalium (ATCC 33530), M. pneumoniae (ATCC 15531), and Ureaplasma urealyticum, isolate UuipT3, recovered in our laboratory. Reference and isolated mycoplasma strains were cultivated in SP-4 medium [16] supplemented with $5 \%$ of CMRL 1066 (Sigma), 2000 units/ml of penicillin G, 500 units $/ \mathrm{ml}$ of polymyxin B, $2.5 \mu \mathrm{g} / \mathrm{ml}$ amphotericin B, $10 \%$ of fresh yeast extract (Amersham Biosciences), 15\% of horse serum (Gibco BRL), and $0.5 \%$ phenol red. The medium was further supplemented with $0.5 \%$ of glucose, $0.5 \%$ of arginine, or $0.5 \%$ of urea depending on the nutritional needs of the species being cultivated. Broth culture was done at $37^{\circ} \mathrm{C}$ and mycoplasma growth confirmation was performed onto SP-4 agar plates maintained at $37^{\circ} \mathrm{C}$ with $5 \% \mathrm{CO}_{2}$ and regularly observed microscopically for the appearance of mycoplasma colonies.

\section{Clinical specimens}

Cervical swabs from 34 female patients suffering from sexually transmissible disease, 23 vaginal specimens from women presenting a number of complications associated to pregnancy, including chorioamnionitis and preterm birth, 29 urethral specimens obtained from men with urethritis, and 6 semen samples from clinical cases associated with infertility. All these specimens were tested for the presence of genital mycoplasmas (M. hominis, M. genitalium, M. fermentans, and Ureaplasma urealyticum) by broth and solid culture, then by PCR. The collected specimens were inoculated onto $1.8 \mathrm{ml} \mathrm{SP}-4$ broth medium and then transferred to the laboratory at $4^{\circ} \mathrm{C}$ within $24 \mathrm{~h}$. Semen samples were also placed in a tube with $1.8 \mathrm{ml} \mathrm{SP-4}$ medium for cultivation attempts. The specimens were processed on arrival or after storage at $-80^{\circ} \mathrm{C}$. After filtration through $0.45 \mu \mathrm{m}$ single use syringe filter, $200 \mu \mathrm{l}$ of the specimen was inoculated into each of SP-4 broth with $0.5 \%$ of glucose and $0.5 \%$ of arginine for the isolation and identification of mycoplasmas and SP-4U broth with $0.5 \%$ of urea for Ureaplasma urealyticum isolation and identification. In parallel, $100 \mu \mathrm{l}$ of the filtrated specimen was inoculated onto each of SP-4 and SP-4U agar plate for the monitoring of mycoplasma or ureaplasma colonies appearance. All broth cultures were incubated at $37^{\circ} \mathrm{C}$ and examined daily for turbidity and $\mathrm{pH}$ change. The broth cultures were subcultured onto agar plates once their $\mathrm{pH}$ changes. The plates were incubated at $37^{\circ} \mathrm{C}$ in a $5 \%$ carbon dioxide environment and examined every two days for the appearance of mycoplasmas or ureaplasma colonies. To confirm the identification of Mycoplasma spp or ureaplasma, PCR assays have been used on positive broth cultures. For mycoplasma titration, dilution culture and subculture were achieved as described elsewhere [17].

This study has been conducted in close conformity with ethical aspects, which were established by the ethical committee of the Tunisian Ministry of Health. The samples were collected in the context of the routine diagnostic activity of the laboratory of Mycoplasma and with the consent of the patients. All the patient files are confidential and none could be identified.

\section{DNA extraction and sample preparation for PCR amplification}

Culture $(8 \mathrm{ml})$ of the cloned mycoplasma strains and clinical samples was centrifuged at $17000 \mathrm{rpm}$ for $30 \mathrm{~min}$, washed in PBS $(0.1 \mathrm{M}-\mathrm{NaCl}, 2.5 \mathrm{mM}-\mathrm{KCl}, 10 \mathrm{mM}$ $\mathrm{Na}_{2} \mathrm{HPO}_{4}, 1.5 \mathrm{mM}-\mathrm{KH}_{2} \mathrm{PO}_{4}, \mathrm{pH}$ 7.4), and then suspended in $200 \mu \mathrm{l}$ of PBS. This concentrated culture was processed for PCR as described elsewhere [18]. Briefly, SDS to a final concentration of $1 \%$ was added to the DNA 
and incubated at $37^{\circ} \mathrm{C}$ for half an hour in the presence of RNase A $(5 \mu \mathrm{g} / \mathrm{ml})$. A volume of $25 \mu \mathrm{l}$ was then used for PCR amplification.

\section{Primers and PCR amplification}

Two pairs of primers were used in this study. The pair Mhp120'F (5'-GAGGAATTTCAACTGGTGTCC-3') and Mhp120'R (5'-CTGTTGTAATAGCATTTAAG-3') was specific to the M. hominis p120' gene. PCR was performed on $25 \mu \mathrm{l}$ of treated sample in a total volume of $50 \mu \mathrm{l}$ containing, $10 \mathrm{mM}$ Tris- $\mathrm{HCl}$ (pH 8.3), $50 \mathrm{mM} \mathrm{KCl,} 2.5 \mathrm{mM}$ $\mathrm{MgCl}_{2}, 250 \mu \mathrm{M}$ of each dNTP (Amersham Biosciences), 50 pmol of each primers, and 1.25 U of Taq DNA polymerase (Amersham Biosciences). The PCR mixtures were subjected to 30 cycles consisting of $1 \mathrm{~min}$ at $95^{\circ} \mathrm{C}, 2$ min at $50^{\circ} \mathrm{C}$, and $1 \mathrm{~min}$ at $72^{\circ} \mathrm{C}$ in a Perkin-Elmer GeneAmp PCR System 9700 thermocycler. After the last cycle, a final extension temperature of $72^{\circ} \mathrm{C}$ was maintained for $10 \mathrm{~min}$. To determine the specificity of $M$. hominis primers, the PCR reaction was performed with DNAs from other mycoplasma species, M. fermentans, M. genitalium, M. pneumoniae, which occasionally has been isolated from urogenital tract, and Ureaplasma urealyticum, strain UuipT3. The PCR products were analysed on 2\% agarose gels. The PCR experiments were repeated at least twice for results confirmation.

\section{Sequence analysis}

The PCR products were separated by electrophoresis in a $1.5 \%$ low-melting-point agarose gel, excised from the gel, and then purified using the GFX PCR DNA and Gel Band Purification system (Amersham Biosciences). Determination of the nucleotide sequence was performed with the Prism Ready Reaction Dye Deoxy Terminator Cycle sequencing Kit on an ABI PRISM 377 DNA sequencer (Applied Biosystems). Each sample was sequenced from two independent PCR amplification reactions.

The sequence data (GenBank accession numbers; pending) were aligned using ClustalW [19] and edited with the software programs BioEdit [20]. DNASP [21] was used to calculate haplotypes and to test for adaptive selection, by determining the nucleotide substitution changes and the ratio of synonymous (Ks) and nonsynonymous (Ka) substitutions per site. For this purpose, we used the analysis developed by Nei-Gojobori [22] as implemented in the DNASP package. A dendrogram illustrating the genetic relatedness of the recovered $M$. hominis isolates was constructed using MEGA version 3.0. [23]. The dendrogram was obtained using the neighbor-joining method with 1000 bootstrapping replicates.

\section{Results}

\section{Isolation, titration and cloning of $\mathbf{M}$. hominis strains}

To determine the initial count of the mycoplasma species contained within the clinical samples, ten-fold dilutions of the original sample were performed and inoculated to SP-4 agar plates. Among the clinical specimens, 27 yielded a high number of viable mycoplasma varying from $10^{5}$ to $10^{6}$ C.F.U. (colony forming unit) $/ \mathrm{ml}$ for $M$. hominis and only $5 \mathrm{M}$. genitalium and $12 \mathrm{U}$. urealyticum isolates were detected by culture with low number $\left(\leq 10^{4}\right.$ C.F.U $\left./ \mathrm{ml}\right)$ (Tab. 1). As mycoplasma cultures obtained from clinical specimens often represent a mixture of several species, especially with $M$. hominis and U. urealyticum, cloning was undertaken so that PCR amplification would involve a DNA template prepared from a single clone. Cloning is also crucial to obtain a real picture of the genetic heterogeneity within a single specie. For this purpose, single colonies from the highest (often the fifth or the sixth dilution) ten-fold dilutions of each specimen culture were picked, cultured into SP-4 broth medium, then diluted through 10 serial dilutions, and finally, $100 \mu \mathrm{l}$ of each dilution was subcultured onto a SP-4 agar plate. This process was repeated thrice and allowed the appearance of typical Mycoplasma hominis colonies in these 27 high tittering clinical specimens. The colonies are clearly distinguishable from those of $U$. urealyticum which are characterized by their tiny size and dark colour.

\section{PCR amplification and genetic diversity of the PI20' surface exposed $\mathbf{N}$-terminal coding sequence}

All the $27 \mathrm{M}$. hominis cloned isolates yielded a PCR product of the expected molecular size (510 bp), suggesting that this gene sequence is highly conserved (Fig. 1). No amplification was observed using DNAs from other mycoplasma species namely, M. genitalium, M. fermentans, $M$. pneumoniae and $U$. urealyticum (Fig. 1, lanes 3-6), thus confirming the specificity of the PCR reaction. The nucleotide sequence encompassing the positions 145 to 565 (421 nucleotides) of the P120' gene sequence (amino acids 49 to 188) was obtained for each sample, by sequencing in both directions, two PCR products from independent amplifications. A total of 25 single nucleotide polymorphisms (SNPs) distributed through 23 polymorphic sites were observed (A162G, T177A, T192G, A212T, A212G, A215G, C234T, T297C, A300G, A300C, A379C, G394A, C396T, A399T, C405T, A409T, A417T, T441A, A482T, C483T, G500T, C509T, A552G, A563G, and T564A), yielding 13 haplotypes. Mutations at positions 234 (C to T) and 394 ( $\mathrm{G}$ to T) were shared by the 27 isolates, whereas the SNPs at positions 297, 300, 379, $396,405,500$, and 552 were found in more than 20 isolates.

Among the 23 polymorphic sites, thirteen (56.5\%) are non synonymous as they cause an amino acid change 


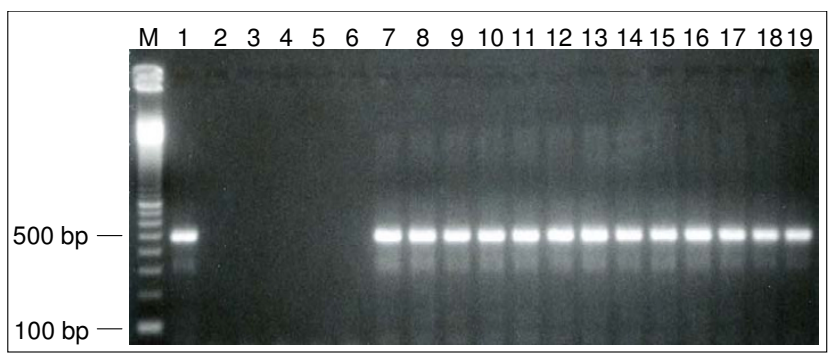

\section{Figure I}

Representative illustration of PCR amplification of the 510-bp fragment of $M$. hominis. $M$ : 100 bp molecular size ladder, lanes I and 7: M. hominis PG2I strain (positive control), lane 2: No M. hominis DNA with Mhp I20' primers (negative control), lanes 3-6: Mhp 120' primers with DNA from M. genitalium ATCC 33530 (lane 3), M. fermentans ATCC 19989 (lane 4), M. pneumoniae ATCC I553I (lane 5), and U. urealyticum UuipT3 (lane 6), lanes 8-19: M. hominis isolates.

(D59E, N64K, E71V, E71G, N72S, K100N, K127Q, V132I, I137F, E139D, D161V, R167I, A170V, and N188R) (Fig. 2). Of these, mutations K127Q, V132I, A170V, and $\mathrm{N} 188 \mathrm{~K}$ were shared by most of the isolates. Overall, the mutations were mainly confined within three regions, 59-72, 127-139, and 161-188, each containing four amino acid changes. We could distinguish 10 haplotypes among the deduced amino acid sequences.

\section{Genetic relatedness of $M$. hominis isolates and evolution of the $\mathrm{N}$-terminal region of $\mathrm{P} / \mathrm{20}^{\prime}$}

The unrooted neighbour-joining-based phylogenetic derived tree (Fig. 3), using the deduced amino acid sequences of the $27 \mathrm{M}$. hominis isolates, showed a major branch containing a group of 17 closely-related isolates and 6 variant emerging strains. This major branch, which is supported by bootstrap, is clearly distinct from that of the reference $M$. hominis strain PG21. The remaining isolates are less phylogentically close to the majority of the pool; Mh13 and Mh8 belonging to a distinct evolutionary tract.

The acquisition rates for sSNP (Ks) and nsSNP (Ka) were calculated in order to evaluate the evolutionary trend of this surface exposed part of the P120' protein. We found that the overall mean value of 0.046 for Ks $(0.011-0.47)$ is significantly different $(P<0.0001)$ from the 0.012 mean value of $\mathrm{Ka}(0.003-0.18)$. The ratio $\mathrm{Ka} / \mathrm{Ks}(0.26)$ is thus $<1$, indicative of a negative selection. This finding is in accordance with a previous study involving housekeeping genes [24].

\section{Discussion}

M. hominis is commonly associated with the normal flora of the female genital tract, in many instances, it was also isolated at high titers from patients with clinical manifestations [7]. Factors relating to host (impairment of local immunity) and to $M$. hominis (essentially selection of immune escape mutants and perturbation of the host cell) have been suggested as a basis for the disruption of the host-pathogen equilibrium and the appearance of clinical disorders [25].

Because M. hominis in the processed samples was at significant high titers, we reasoned that sufficient replication would have occurred in the face of the immune system of the host and, thus, it could be an opportunity to evaluate the genetic variability of surface exposed proteins. We focused our analysis on P120' protein, a homolog of P120, which unlike the latter, seems to be less subjected to genetic variability $[10,26]$, and whose function remains to be determined. We targeted the N-terminal region of the P120' protein as it has been previously shown to be surface exposed [10]. Our results show that significant variability among the different isolates has accumulated, although the time frame in which the isolates were obtained is relatively short. This finding is in fair agreement with a previous study that showed that M. hominis isolates from different individuals always differed, a finding explained by the occurrence of intergenic recombination [24]. One can argue that higher variability would have been observed if samples collected over extended time periods were analysed. However, one cannot also dismiss the possibility that increased genetic variability could have been observed among isolates belonging to different geographical origins. This might be reflected, in our study, by the fact that the English M. hominis reference strain, PG21, differed from most of the Tunisian isolates in 4 of the varying sites. In fact, the latter strain also differed from all the isolates included in Sogaard's study. As far as could ascertained, as a reference strain, PG21 could have been subjected to several passages and transferred to many laboratories, thus contributing to its apparent divergence.

All but one mutation was confined within three distinct regions, suggesting that they might be under selective pressure. Hence, although the surface exposed region, analysed as a whole, appears to be naturally under negative selection $(\mathrm{Ka} / \mathrm{Ks}<1)$, the three main variable regions might evolve towards the accumulation of higher non synonymous changes, and may thus represent variable evolving domains. Within the pool of recovered isolates, a predominant group of closely-related strains was identified. Phylogenetic analysis showed that variants from this group tend to emerge. It remains to be seen, through analysis of larger samples over extended periods of time, whether emergence of these variants is a result of the host immune pressure. It is worthy of mentioning that P120' is weakly recognised by patient sera, thus immune selection 


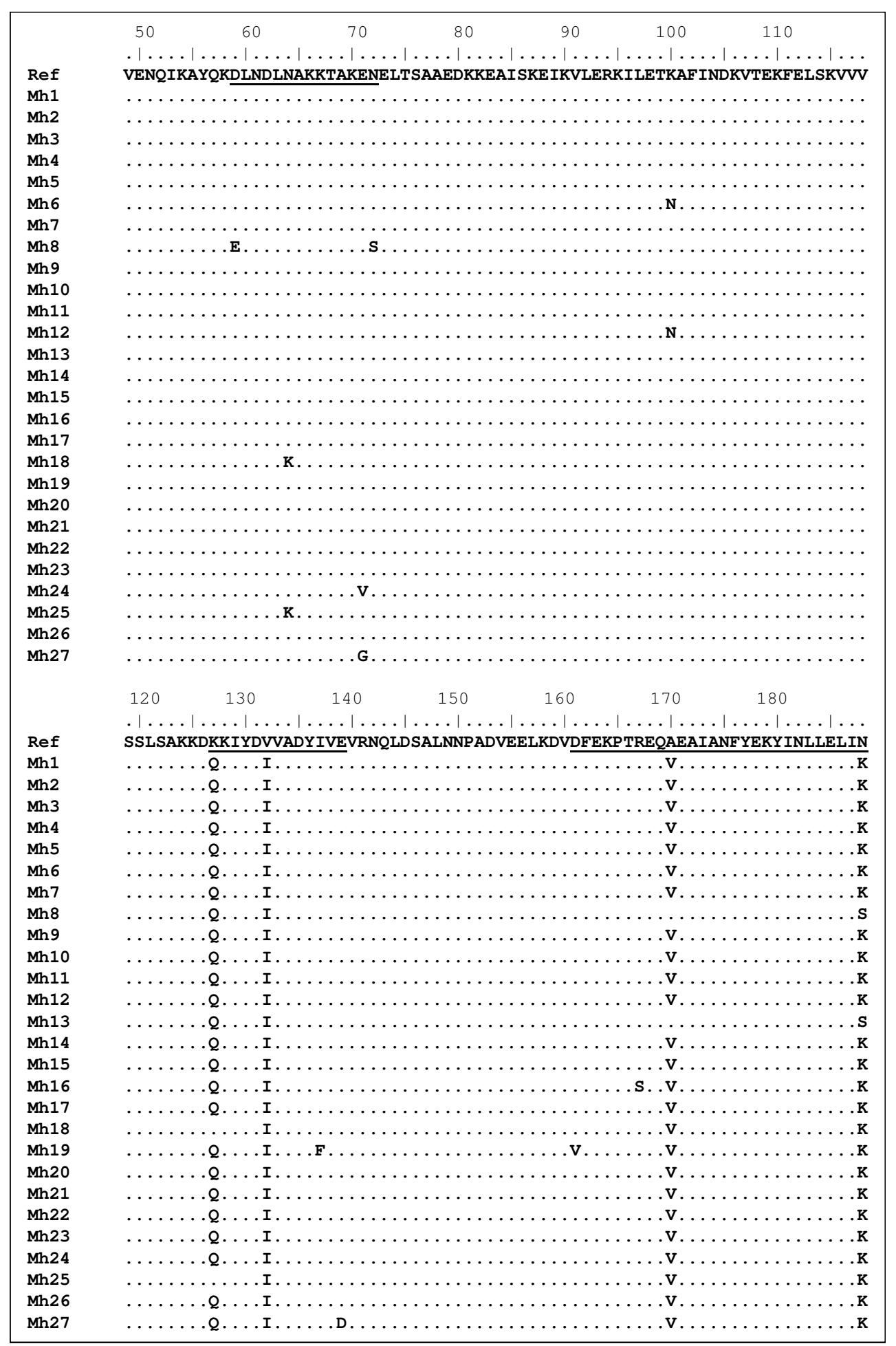

\section{Figure 2}

Multiple alignment of the deduced amino acid sequences of the PI20'surface exposed region of M. hominis isolates (MhI to Mh27) relative to the reference strain PG2I. Dots indicate identical residues. The 3 regions where amino acid changes which tend to occur are underlined. 


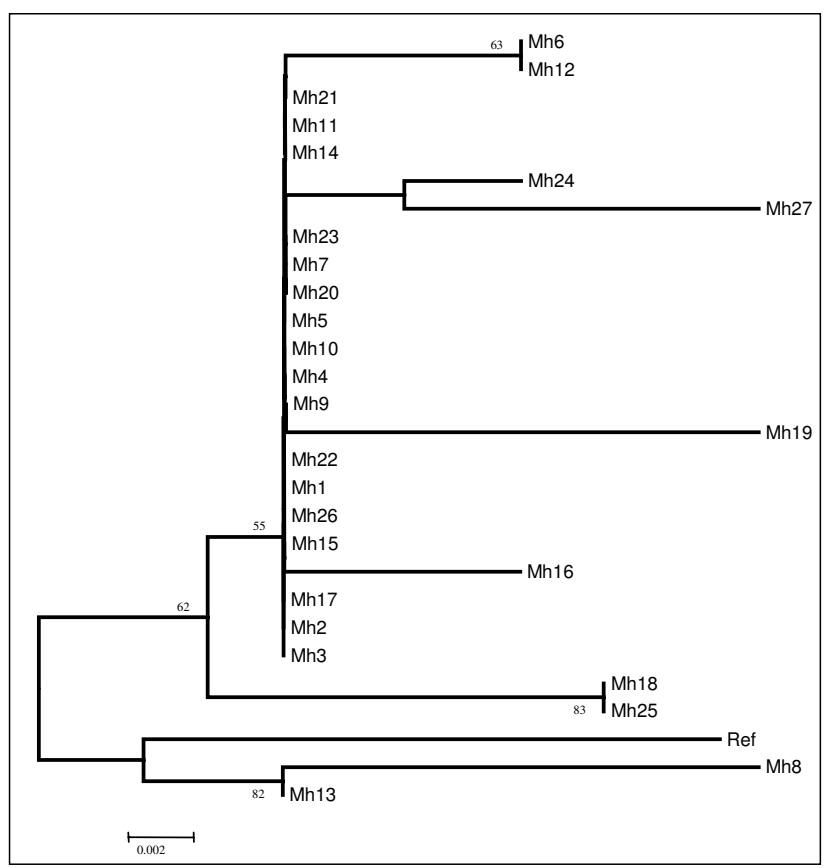

Figure 3

Dendrogram showing the phylogenetic relationships among the $27 \mathrm{M}$. hominis isolates based on their deduced amino acid sequences. The neighbour-joining-based consensus tree was generated upon 1000 data sets. Ref: M. hominis PG2I strain.

may occurs through long-term periods or it may be the result of a cellular immune response.

\section{Conclusion}

Overall, this study showed that the homolog of the variable surface exposed P120 protein, P120', was subjected to genetic variability in its surface exposed domain despite its low reactivity with patient sera. Since both genes seem to have evolved through gene duplication and genetic divergence, they would certainly assume distinct essential functions as they are both conserved and expressed within a single strain. This situation contrasts with other mycoplasmas, such as the avian M. gallisepticum [15] and $M$. synoviae [27], whereby only one member of the family of the variable antigens is expressed. M. homonis does not seem to follow this restrictive strategy as, apart from P120 and P120', at least two other variable proteins, Lmp and Vaa, contribute to its variability.

\section{List of abbreviations}

SNP: Single nucleotide polymorphism

sSNP: synonymous single nucleotide polymorphism

nsSNP: nonsynonymous single nucleotide polymorphism

\section{Competing interests}

The author(s) declare that they have no competing interests.

\section{Authors' contributions}

All authors read and approved the final manuscript. BBAM, overviewed the work, performed the sequencing analysis and wrote the manuscript. HA, conducted the PCR amplification and performed the sequencing reactions. ABK, repeated and confirmed the sequencing analysis and helped in reviewing the manuscript. BM and FA performed the clinical specimens' treatment, the mycoplasmas culture and cloning. IM, carried out the PCR amplification of Mycoplasma hominis isolates and other genital Mycoplasma spp for specificity evaluation.

\section{Acknowledgements}

This study was funded by an internal grant provided by the Institut Pasteur de Tunis.

\section{References}

I. Razin S, Yogev D, Naot Y: Molecular biology and pathogenicity of mycoplasmas. Microbiol Mol Biol Rev 1998, 62(4): I094-I I 56.

2. Woese CR: Bacterial evolution. Microbiol Rev 1987, 5 I(2):22I-27I.

3. Pereyre S, Avenaud P, Charron A, Sirand-Pugnet P, Jacob D, Couloux A, Barbe V, Daruvar A, Blanchard A, Bébéar C: The complete genome sequence of the human urogenital mycoplasma, Mycoplasma hominis [abstract]. 16th International Congress of the International Organization for Mycoplasmology 2006:4I-42.

4. Kramer DG, Brown ST: Sexually transmitted diseases and infertility. Int J Gynaecol Obstet 1984, 22:19-27.

5. Cassell GH, Waites KB: Venereal mycoplasmal infections. In Infectious diseases: a modern treatment of infectious processes Edited by: Hoeprich PD, Jordan MC. Lippincott JB, Philadelphia PA; 1989:632-638.

6. Meyer RD, Clough W: Extragenital Mycoplasma hominis infections in adults: emphasis on immunosuppression. Clin Infect Dis 1993, 17:243-249.

7. Mardh PA: Mycoplasmal PID: a review of natural and experimental infections. Yale J Biol Med 1983, 56:529-536.

8. Tully JG: Mollicutes: Mycoplasma pneumoniae and Mycoplasma genitalium. Current status of the Mollicute flora of humans. Clin Infect Dis 1993, 17:2-9.

9. Waites KB, Duggy LB, Crouse DT, Dworsky ME, Strange MJ, Nelson $\mathrm{KG}$, Assell GH: Mycoplasmal infection of the cerebrospinal fluid in newborn infants from a community hospital population. Pediatr Infect Dis J 1990, 9:24I-245.

10. Ladefoged SA, Christiansen G: Mycoplasma hominis expresses two variants of a cell-surface protein, one a lipoprotein, and one not. Microbiology 1998, 144:761-770.

11. Ladefoged SA, Jensen LT, Brock B, Birkelund S, Christiansen G: Analysis of 0.5-kilobase-pair repeats in the Mycoplasma hominis Imp gene system and identification of gene products. J Bacteriol 1996, I 78:2775-2784.

12. Zhang Q, Wise KS: Coupled phase-variable expression and epitope masking of selective surface lipoproteins increase surface phenotypic diversity in Mycoplasma hominis. Infect Immun 200I, 69:5I77-5I8I.

13. Zhang Q, Wise KS: Molecular basis of size and antigenic variation of a Mycoplasma hominis adhesion encoded by divergent vaa genes. Infect Immun 1996, 64:2737-2744.

14. Markham PF, Glew MD, Sykes JE, Bowden TR, Pollocks TD, Browning GF, Whithear KG, Walker ID: The organisation of the multigene family which encodes the major cell surface protein, pMGA, of Mycoplasma gallisepticum. FEBS Lett 1994, 352:347-352.

15. Markham PF, Glew MD, Whithear KG, Walker ID: Molecular cloning of a member of the gene family that encodes PMGA, a 
hemagglutinin of Mycoplasma gallisepticum. Infect Immun 1993, 6I:903-909.

16. Tully JG, Whitcomb RF, Clark HF, Williamson DL: Pathogenic mycoplasmas: cultivation and vertebrate pathogenicity of a new spiroplasma. Science 1977, 195:892-894.

17. Taylor-Robinson D, Furr PM: Recovery and identification of human genital tract mycoplasmas. Isr J Med Sci I98I, 17:648-653.

18. Mardassi BB, Ben-Mohamed R, Gueriri I, Boughattas S, Mlik B: Duplex PCR to differentiate between Mycoplasma synoviae and Mycoplasma gallisepticumon the basis of conserved species-specific sequences of their hemagglutinin genes. J Clin Microbiol 1995, 43:948-958.

19. Thompson JD, Desmond GH, Toby JG: ClustalW: improving the sensitivity of progressive multiple sequence alignment through sequence weighting, position-specific gap penalties and weight matrix choice. Nucleic Acids Res 1994, 22:4673-4680.

20. Hall TA: BioEdit: A user-friendly biological sequence alignment editor and analysis program for Windows 95/98/NT. Nucleic Acids Symp 1999, 41:95-98.

21. Rozas J, Sanchez-DelBarrio JC, Messeguer X, Rozas R: DnaSP, DNA polymorphism analyses by the coalescent and other methods. Bioinformatics 2003, 19:2496-2497.

22. Nei M, Gojobori T: Simple methods for estimating the numbers of synonymous and nonsynonymous nucleotide substitutions. Mol Biol Evol I 986, 3:4I8-426.

23. Kumar S, Tamura K, Nei M: MEGA3: integrated software for molecular evolutionary genetics analysis and sequence alignment. Breif Bioinform 2004, 5:150-163.

24. Sogaard IZ, Boesen T, Mygind T, Melkova R, Birkelund S, Christiansen G, Schierup MH: Recombination in Mycoplasma hominis. Infect Genet Evol 2002, I:277-285.

25. Horne HWJr, Kendsin RB: The role of mycoplasma among $8 \mathrm{I}$ consecutive pregnancies: a prospective study. Int J Fertil 1980, 25:3|5-3|7.

26. Nyvold C, Birkelund S, Christiansen G: The Mycoplasma hominis PI 20 membrane protein contains a 216 amino acid hypervariable domain that is recognized by the human immune response. Microbiology 1997, 143:675-688.

27. Noormohammadi AH, Markham PF, Kanci A, Whithear KG, Browning GF: A novel mechanism for control of antigenic variation in the haemagglutinin gene family of Mycoplasma synoviae. Mol Microbiol 2000, 35:9I I-923.

\section{Pre-publication history}

The pre-publication history for this paper can be accessed here:

http://www.biomedcentral.com/1471-2334/7/142/pre

pub
Publish with Biomed Central and every scientist can read your work free of charge

"BioMed Central will be the most significant development for disseminating the results of biomedical research in our lifetime. "

Sir Paul Nurse, Cancer Research UK

Your research papers will be:

- available free of charge to the entire biomedical community

- peer reviewed and published immediately upon acceptance

- cited in PubMed and archived on PubMed Central

- yours - you keep the copyright

Submit your manuscript here:

http://www.biomedcentral.com/info/publishing_adv.asp
BiolMedcentral 